\title{
Title:
}

\section{Old Country Passions: An International Examination of Country Image, Animosity, and} Affinity among Ethnic Consumers

\begin{abstract}
:
Ethnic consumers are an important market segment in both traditionally multicultural countries as well as newer recipients of growing immigration movements. Such consumers may carry with them views toward "old friends and foes" which may influence their attitudes toward the products of countries perceived as friendly or hostile in relation to their original home countries. This study examines together for the first time four place-related constructs, namely, country and people images, product images, affinity, and animosity, and their potential effects on purchase intentions, juxtaposing these measures against views toward countries that may be perceived as friendly or hostile from the perspective of the ethnic consumers' homeland, alongside a neutral "benchmark" country for comparison. The results show that country/people and product images, affinity, and animosity work differently depending on the target country, product and people evaluations are influenced by both affective and cognitive factors, and attitudes vary in their predictive ability on purchase intentions, sometimes in line with earlier findings and sometimes not. Implications and directions for future research are discussed.
\end{abstract}

\section{Keywords:}

Country image, Animosity, Affinity, Ethnic consumers 


\section{INTRODUCTION}

The influx of immigrants and refugees in host countries over the past few decades, and their potential as significant markets, makes it vital to understand ethnic consumers' consumptionrelated behaviours. For instance, in his review of the relevant literature Cui (2001) noted that three ethnic groups in the U.S. (African, Asian, and Hispanic Americans) represent 25\% of the population and account for a trillion-dollar growth market. The issue is important both in traditionally multicultural societies (e.g., U.S., Canada, Australia), as well as in other countries that are experiencing growing immigration (e.g., in Europe). This results in large ethnic groups that are rapidly changing the host countries' demographic profiles and are shaping new communities with strong ties to their homelands. In international marketing, this raises the question of whether ethnic consumers carry with them "old country passions" when assessing foreign products depending on their country of origin. In other words, might the images of products from countries that are perceived as "friendly" or "hostile" from the viewpoint of an ethnic consumer's "old country" affect purchase intentions for products from those countries?

Research on country of origin or Product-Country Image (PCI) effects investigates consumer evaluations of products based on the image of the country with which they are associated. Over time, contributions in this field have dealt primarily with the image of a product, depending on where it is actually made or on its brand origin (Samiee 2011); the image of the origin country itself and its people, as distinct from that of its products (Roth and Diamantopoulos 2009); and combined examinations of the effects of the former on the latter (Martin and Eroglu 1993; Knight and Calantone 2000). Yet even though the role of country image as a powerful predictor of product evaluations is widely recognized, several research gaps remain. This is especially so in relation to two constructs that emerged more recently: animosity, 
which reflects negative views directed at a specific country (Klein, Ettenson, and Morris 1998); and its counterpart, affinity, which is also country-specific but reflects positive attitudes (Oberecker, Riefler, and Diamantopoulos 2008).

Research on consumer animosity has been growing substantially since the construct was first examined almost two decades ago, while the substream on consumer affinity is still in its nascent stage (Oberecker and Diamantopoulos 2011). The vast majority of animosity studies have dealt with old instead of current enmities, such as China vs. Japan in Klein, Ettenson, and Morris (1998) and Holland vs. Germany in Nijssen and Douglas (2004), even though consumer views may differ substantively from those referring to more recent conflicts.

Furthermore, and of particular interest in the present study, animosity and affinity research have not differentiated between types of consumers, even though a strong case can be made that their views may differ not only along traditional demographic factors but also, and more importantly, in terms of their ethnicity. The growth of global mobility has led Berking (2003, p. 248) to observe that "Ethnicity is Everywhere", thus making ethnic consumer behaviour a matter of great interest in country image research and international marketing in general.

An additional and important gap comprises three inter-related dimensions. First, animosity and affinity have been studied separately from each other, even though they may be implicitly assumed to be each other's mirror-images (high animosity would imply low affinity toward a country, and vice-versa); therefore, their potentially distinct versus interactive effects, in terms of which may be the principal driver of buyer behaviour, have not been explored. Second, there is a dearth of empirical research on affinity, the most recently-proposed of these two constructs. And third, studies to date have examined attitudes toward one country only, which means that consumer responses may not be unique to that country and may in fact be meaningless in the context within which they are being researched. To further clarify this important point, 
ascertaining the presence of country-specific affinity or animosity among consumers toward country $\mathrm{X}$ would be meaningful only if such feelings were unique to $X$ and did not also extend to other countries not included in the study.

As a result of the above research gaps, the affinity and animosity constructs are not well understood individually, let alone in relation to each other. Ethnic consumers' potentially strong views toward countries that are positively or negatively associated with their ethnic origin provide a unique opportunity to study affinity and animosity in the country image context. In this light, rather than attempting to add to the rich literature on the principal constructs of country/people and product images, the objectives of the present study, and therefore its motivation and intended primary contribution, are to contribute to and advance country image theory by examining for the first time (a) country-product association effects in the context of current and long-lasting (b) affinity and (c) animosity, $(d)$ comparatively toward specific countries that might be the targets of such feelings (e) among ethnic consumers.

More specifically, this study is designed to contribute to PCI, animosity, affinity, and ethnicity theory by attending to the research gaps mentioned above in terms of six interrelated elements. First, it employs an ethnic consumer sample, so as to address the lack of differentiation by type of consumer in past research. Second, it is framed in the context of long-lasting animosity and affinity feelings that carry over into the contemporary context, which helps avoid potential confounds from older feelings of like or dislike that may have receded from current consumers' memories. Third, it advances the theory of animosity and affinity by studying both constructs concurrently, whereas extant research has only investigated each separately from the other. Fourth, the study brings together for the first time both the principal constructs of country/people and product image as well as the newer ones of animosity and affinity in a concurrent investigation within a single research context. Fifth, it examines consumer attitudes in relation to 
three countries that are typically viewed in positive ("affinity country"), negative ("animosity country"), and neutral ("benchmark country") terms in relation to the consumer's ethnic origin, which makes it possible to consider whether animosity and affinity are or are not unique to the respective target countries. And sixth, by investigating the affinity construct the study helps to address the dearth of empirical research in this new field.

The main sections in the remainder of this paper present an overview of the theoretical underpinnings and hypotheses of the study, follow with the methodology, data analysis, and results, and discuss key conclusions, research and managerial implications, and limitations and directions for future research.

\section{THEORETICAL DEVELOPMENT AND HYPOTHESES}

The notion of country image effects, which posits that the images of countries, their people, and their products affect consumer behaviour, was used as the overarching theory in guiding this study. Within the PCI construct, the sub-stream of animosity theory holds the same tenets, namely, that antipathy or antagonism toward a specific country have a negative effect on willingness to buy its products, and, even though less well developed, so does the theory behind the affinity construct albeit in the reverse, positive direction.

Country image is defined as "a three-dimensional concept consisting of cognitive, affective, and conative components" (Laroche et al. 2005, p. 96), which refer, respectively, to one's beliefs, feelings, and behavioural intentions toward the attitude object (Ajzen 1989). This view is consistent with the tripartite conceptualization of attitude that is common in this field (e.g., Vida and Reardon 2008; Las Casas and Silverio 2015; Zeugner-Roth and Žabkar 2015) and is well established in marketing research in general (e.g., Bagozzi et al. 1979; Li et al. 2014). The construct is an extrinsic cue that typically comprises elements of the country itself (e.g., political 
stability, technological development), its people (e.g., trustworthy, likeable), and its products (e.g., innovative, high quality), thereby facilitating product judgements by consumers. Extrinsic cues influence attitudes significantly even when consumers may be familiar with a product's intrinsic features (Lee and Lou 2011). In addition to its cognitive content, the PCI cue carries with it symbolic and emotional meaning that activates affective feelings, such as the pride consumers may feel in owning a country's products (Papadopoulos, Heslop, and IKON 2000). In turn, the cognitive and affective dimensions of attitude have been connected directly to its conative component (Eagly and Chaiken 1993), representing the intent or lack thereof to buy those products (Rezvani et al. 2012).

In PCI theory, which forms the principal theoretical base for this study, past research has examined at length a number of issues associated with the country/people and product constructs. These include, for example, image effects on products from emerging countries (Touzani, Smaoui, and Labidi 2015) and a large variety of moderators of the country-product relationship, such as familiarity (Lee and Robb 2016) and brand typicality (Hamzaoui-Essoussi, Merunka, and Bartikowski 2011). Similarly, the study is also informed by insights from cogent theoretical domains in social psychology that are also heavily researched in international marketing, including ethnicity and acculturation, and by findings within the animosity and affinity substreams in country image research.

Ethnic consumers are defined as those who live in a country different from their homeland, share a common ancestry and unique ethnic characteristics associated with it (Cui 2001), and have a sense of identification with the group associated with their ethnicity (Burton 2000). Ethnicity theory is grounded on the notion that, as ethnic consumers grapple with the need to negotiate cross-cultural differences between their home and host countries (Ting-Toomey 2005), they may undergo identity transformations that can lead to greater or lesser degrees of 
acculturation to their host environment (Kim 2008). Ethnicity is well-established as a driver of consumer behaviour (Jafari and Visconti, 2015; Zeugner-Roth, Žabkar, and Diamantopoulos 2015) and can have a powerful influence on consumption patterns (Hamlett et al. 2008). As a result, the influence of acculturation on marketplace behaviour is textured (Cleveland et al. 2009): Acculturation, or the process of adopting the tenets of a culture different from that of one's ethnicity, is a complex phenomenon that "need not necessarily entail the shedding of original culture values and behaviours" (Cleveland and Laroche 2007, p. 250). As they develop their "intercultural personhood" (Kim 2008), ethnic consumers may well have different attitudes and preferences from those of the main population of the host country and often show a preference for "home" products (Duruz 2000; Cleveland et al. 2009; Lindridge, 2010). Of particular relevance to the present study, research on ethnic consumers shows that ethnicity influences their perceptions of products from countries linked to their ethnic origin (Wang 2005; Podoshen 2009; Little and Singh 2014).

Animosity, which may be due to such reasons as previous or ongoing territorial, religious, or ethnic disputes, was first put forth in international marketing research by Klein, Ettenson, and Morris (1998) who defined it as antipathy or anger (Klein 2002) toward a specific country. While these early works did not refer to any antecedent theories for the animosity construct, subsequent studies established its relationship to emotion in social psychology and, in particular, to ingroupoutgroup theory (e.g., Huitzilin Jiménez and San Martín 2010; Harmeling, Magnusson, and Singh 2015; Shimp, Dunn, and Klein 2004). This was pioneered by Tajfel (1982) in his integrative theory on intergroup relations and conflict, and is central to understanding the underlying mechanisms of animosity (Huang, Phau, and Lin 2010). As noted by Nijssen and Douglas (2004, p. 27), the ingroup-outgroup distinction reflects, respectively, feelings of "identity and close attachment" versus "separateness, opposition or even hatred" and has been 
studied extensively in social psychology (Macrae \& Quadflieg (2010). Animosity differs from ethnocentrism, which also draws on ingroup-outgroup theory and refers to general beliefs about the superiority of one's own country's products (Wang 2005). Thus animosity depends on the country(ies) in question and may be transient, as in the cases of Australian attitudes to France resulting from the latter's nuclear testing in the Pacific (Heslop, Lu, and Cray 2009) and British public opinion changes toward Germany before, between, and after WWI and WWII (Amine, Chao, and Arnold 2005), or last a long time, such as the Holocaust effects on Jewish consumers' (un)willingness to buy German products (Podoshen 2009) and South Korea's post-WWII fiftyyear ban on Japanese products, which was removed only in 2002 (Leong et al. 2008). Several studies have found that animosity influences willingness to buy directly, without necessarily affecting beliefs about the quality of the country's products (Riefler and Diamantopoulos 2007; Harmeling, Magnusson, and Singh 2015), but studies into longer-term antipathies have found an effect on quality beliefs as well (Heslop, Lu, and Cray 2009; Shoham and Gavish 2016).

Affinity is also related to ingroup-outgroup theory, and Oberecker and Diamantopoulos (2011) note that it can lead to including select outgroups as part of one's ingroup. Due to the very early state of research in this area the construct's theoretical composition and dimensionality are yet to be explored, but consumer affinity is generally defined in terms of feelings of liking, sympathy, or attachment toward a specific foreign country, which may act as important predictors of buying behaviour (Oberecker and Diamantopoulos 2011). This view is consistent with affinity research in other contexts, such as marketing to diasporas, or groups of people who live outside their homeland (Butler 2001), which leverages ethnic consumers' home-country identification (Kumar and Steenkamp 2013). Affinity feelings may be directed at culturally-proximate countries (Oberecker, Riefler, and Diamantopoulos 2008; Swift 1999), or, as recently noted by Nes, Yelkur, and Silkoset (2014), they may be associated with "attractive places" which appeal to 
one's social identity. Cultural proximity is particularly relevant in the case of ethnic consumers, who are linked to their country of affiliation by virtue of their heritage (Heslop, Papadopoulos, and Bourk 1998; Oberecker and Diamantopoulos 2011). The limited empirical research in this area suggests that feelings of affinity may impact willingness to buy directly without involving much cognitive judgement (Vida and Reardon 2008).

In summary, extant research shows that marketplace behaviour may be influenced by negative or positive views toward the country with which a product is associated, and that ethnicity, in particular, affects attitudes toward ethnically-linked countries. This conclusion led to the development of the conceptual framework in Figure 1, which served as the foundation for operationalizing the four constructs of interest in this study (country/people image, product image, animosity, and affinity). While recognizing that consumer views are multi-dimensional, we use the terms "animosity country", "benchmark country", and "affinity country" in line with the focus of the study, as expressed in its intended contribution, on pre-selecting potential targets for investigation so as to examine comparatively whether negative, neutral, or positive views are unique to the country in question from the homeland perspective of ethnic consumers.

Since ethnic consumers may carry "old country passions" to their current home, attitudes are expected to differ among the three countries and to affect consumers' likelihood to buy their products. The framework focuses attention on contrasting attitudes and intentions toward the three countries in terms of the key constructs, instead of examining relationships among these constructs (e.g., country/people effects on product image) or antecedents and moderators that have already been studied at length in extant research, and leads to the study's hypotheses.

\section{Figure 1 about here}

Country/people and product measures from mainline PCI research comprise the principal means for evaluating country images and provide valuable insights that enhance those developed 
specifically within the animosity and affinity sub-streams (e.g., Oberecker and Diamantopoulos 2011; Shoham et al. 2006). One key purpose of this research is to examine the main factors that contribute to purchase intentions toward a country's products, by including in the same study measures for the country/people and product constructs from mainstream PCI theory. While research is inconclusive as to whether animosity affects both product beliefs and purchase intent versus having only a direct effect on the latter, the broader PCI literature clearly supports the view that product beliefs are influenced by country image. Therefore, we would expect ethnic consumers to evaluate countries, people, and products in line with the following hypotheses: H1a: Country/people evaluations will be lowest for the animosity country, highest for the affinity country, and between the previous two for the benchmark country.

H1b: Product evaluations will be lowest for the animosity country, highest for the affinity country, and between the previous two for the benchmark country.

This study aims to examine concurrently and contrast animosity and affinity in relation to countries that are assumed to be targets of the respective attitudes, while also using a benchmark country for comparison. Following this theoretical thread, animosity and affinity should be highest for country/people and product evaluations in, respectively, pre-identified animosity and affinity countries. The benchmark country should be viewed in more neutral terms that do not necessarily imply either positive or negative feelings. This leads to the second set of hypotheses: H2a: Consumer animosity will be highest for the animosity country, lowest for the affinity country, and between the previous two for the benchmark country.

H2b: Consumer affinity will be lowest for the animosity country, highest for the affinity country, and between the previous two for the benchmark country.

As discussed above, existing research has studied extensively the structure and main components of country/people and product images and concluded that these may comprise such 
factors as technological advancement, product quality, or affect. Similarly, while the dimensionality of affinity has not yet been explored, the bulk of animosity research distinguishes between "war/political" and "economic" facets (Klein, Ettenson, and Morris 1998) and the animosity construct has been extended recently to include "people" animosity (Nes, Yelkur, and Silkoset 2014). However, while the evaluations of countries in terms of such components may differ, there are no suggestions that the structure of these evaluations will also differ depending on the country. Said differently, the components of PCI in country/people and product evaluations are expected to remain consistent despite differences in purchase intent. Therefore, H3: The components of country/people image, product image, animosity, and affinity will be similar for the animosity, affinity, and benchmark countries.

Last but not least, building on our intended contribution through the concurrent examination of the four constructs, a primary objective of the study is to examine the interrelationships among these constructs in terms of their relative impact as predictors of purchase intent. That is, we expect each construct to have a significant relationship with purchase intention, albeit in different directions. Drawing on past research findings in various sampletarget country contexts, the following hypotheses are intended to capture both the individual (H4a-H4d) and relative (H4e-H4g) effect of each construct on likelihood to purchase:

H4a: The higher the country/people evaluation, the greater the consumer's likelihood to purchase products affiliated with that country.

H4b: The higher the product evaluation, the greater the consumer's likelihood to purchase products affiliated with that country.

H4c: The higher the level of animosity toward a country, the lower the consumer's likelihood to purchase its products. 
H4d: The higher the level of affinity toward a country, the higher the consumer's likelihood to purchase its products.

Theory in psychology posits that negative affect has a greater and more lasting impact on a person's psychological well-being (Russel and Carroll 1999). Consistent with this view, we expect that the negatively valenced animosity construct will be the most powerful predictor of purchase intentions. However, where there is an absence of negative affect, we expect positively valenced variables (affinity) to be the most powerful predictor of purchase intentions, consistent with the literature on positive affect and judgement (Russel and Carroll 1999). Where neither a negative or positive valenced relationship exists, we expect PCI cues to be the strongest predictors of purchase intentions.

H4e: Animosity will predominate in predicting likelihood to purchase animosity country products, followed in this order by affinity, country/people image, and product image.

H4f: Affinity will predominate in predicting likelihood to purchase affinity country products, followed in this order by animosity, country/people image, and product image.

H4g: Country/people image and product image will predominate as the predictors of likelihood to purchase from the benchmark country, followed in this order by affinity and animosity.

\section{METHOD}

The study's conceptualization calls for examining country image from the perspective of ethnic consumers, with a focus on countries that may give rise to "old passions" in terms of animosity and affinity along with the simultaneous use of a neutral country used as a benchmark.

Egyptian Canadians were selected as the sample, as they are known to have a strong affiliation with their ethnically-linked "home" country (Heinbecker and Momani 2010) and are one of the largest Arab ethnic groups in Canada (Statistics Canada 2011). The economic, cultural, 
and other differences between Egypt and Canada are pronounced, which helps to avoid confounds due to home-host country similarities.

Consistent with the research design, the choice of an Egyptian Canadian sample was ideal for testing the relationships at the study's core. Israel and Tunisia were selected respectively as the animosity and affinity countries. The rationale for selecting Israel lies in its historical relationship with Egypt, which has ranged from fraught and unsettled to strongly antagonistic at various times. Despite a 1979 peace treaty, animosity in this case reflects the construct's previously cited definition in terms of antipathy or anger, going back to several wars and conflicts (e.g., 1956 Suez Crisis, wars of 1967 and 1973, 1967-1982 Israeli occupation of the Sinai), strongly different views on the continuing Israeli-Palestinian conflict, and the cultural, religious, and ethnic differences between the two peoples. The rationale for Tunisia as the affinity country was the reverse, with reference to its religious and cultural similarities with Egypt from as early as the Fatimid civilization (909-1171), which was based in Tunisia with Egypt as the centre of caliphate. More recently, the two countries have signed a number of agreements to facilitate free trade (Bicchi 2011), and, after working to address tensions arising from the 200809 global financial crisis and the 2011 Arab Spring, continue to cooperate in various areas, sponsor events to further strengthen their relationship, and refer to each other as "sister countries" (e.g., Barhouma 2014; Daily News Egypt 2016).

As noted previously, a key weakness of past animosity and affinity research has been a focus on a single target country each time, which may result in substantive research confounds. Building on the examples cited earlier, a view of animosity/affinity toward Israel/Tunisia would mean little if respondents held similar feelings toward "all" or "many other" foreign countries as well. The best way to tell whether such feelings are unique to a country(ies) or universal is to include a comparison benchmark. (Note: The first of three studies reported in Oberecker and 
Diamantopoulos (2011), which focused on affinity, referred to using a neutral country for comparison and mentioned the collection of data relating to it. However, that idea, which helped to partly inspire the design of our study, was not discussed further within that article and to the best of our knowledge has not been taken up in subsequent research.) For this reason a third, "neutral" country was included in this study. Brazil was selected for this purpose, as a review of political and other relationships indicated that it is neutral in the Arab-Israeli context.

The study was a survey using a structured, self-administered research instrument. Past studies have examined a variety of known difficulties in identifying and sampling minority ethnic respondents within broader populations, especially when the subject of the research is sensitive, and suggest a number of approaches for addressing them (e.g., Peñaloza 1994; Pires, Stanton, and Cheek 2003). Several of these approaches were adopted for use in this study. Specifically, participants were selected via a mixed-method procedure using both random area sampling and a purposive selection of members of the Egyptian Canadian community, based on the criteria of achieving variety and contrast that have been developed specifically for sampling ethnic populations (Peñaloza 1994). In particular, purposive sampling enables the systematic selection of a diverse sample based on the respondents' "suitability and ability to provide insights that are relevant to the particular study" (Leahy 2011, p. 655). The questionnaire was distributed both online and in hard copy using the snowball technique, with help from key informants who have been shown to be effective in influencing their social circles to participate in online research (Yang, Mai, and Ben-Ur 2012). In line with past research on ethnicity (e.g., Kazarian and Boyadjian 2008), respondents were asked to self-identify as members of the target ethnic group. Response rates, at 30\% from the online and $49 \%$ from the hard-copy distributions, were highly satisfactory especially when contrasted to, respectively, an average of $18 \%$ for online surveys (Shiha and Fan, 2009) and a range of $27 \%$ to $51 \%$ for traditional hard-copy methods 
specifically in international business (Yang, Wang, and Su 2006). Comparisons of responses between the two distribution methods and between complete and partially-complete questionnaires, intended to assess potential non-response bias, showed no statistically significant differences. Following data cleanup, a total usable sample comprising 308 Egyptian Canadians was obtained. This sample size is considerably larger than those used in similar ethnic consumer studies (Pires, Stanton, and Cheek 2003) as well as in animosity research, where "most studies are based on 150-250 respondents" (Riefler and Diamantopoulos 2007, p. 102).

The demographic profile of the final sample was suitable for the purposes of the study and reasonably reflective of the Egyptian Canadian population. The proportions of male and female participants were $46 \%$ and $54 \%$, the sample had a good age distribution, with $80 \%$ of the total in the 20-49 age range which is highly active in the marketplace, and a noticeable majority of $85 \%$ were college or university graduates. This is consistent with education levels of "biculturals" (Kumar and Steenkamp 2013), and of the Arab population of Canada, which is "twice as likely as other Canadians to have a university degree" (Statistics Canada 2007, p. 7). Furthermore, the most educated individuals, who tend to be opinion leaders and therefore desirable subjects in marketing research, are also more likely to reply to international surveys, which is why the large representation of educated consumers is very common in such studies (Cleveland, Laroche, and Papadopoulos 2009). The sample also reflects the relative recency of immigration to Canada by individuals of Arab origin, with a majority having arrived in the 1990s and only about $8 \%$ in the 1960s or earlier (Statistics Canada 2007). Of the 308 subjects, 36 (12\%) were born in Canada, 37 (12\%) in other countries, and 235 (76\%) in Egypt, and 95\% of both of the participants' parents were born in Egypt. The average number of years of residency in Canada for those born outside the country was 12.4 , with a standard deviation of 9.6. 
The measures employed in this study were derived from earlier research that affirms their usefulness and suitability for this kind of investigation, and were structured as 7-item Likert agree/disagree scales.

Product Evaluations (PRO), Country+People Evaluations $(C+P)$, and Likelihood to Purchase (LTP). Measures for these constructs, which are the most commonly used in mainline PCI research, were drawn from the scales developed, tested, and validated in a variety of studies from Parameswaran and Pisharodi (1994) onwards. Unlike most earlier studies, which used a single conative variable, most typically "willingness to buy" (Ahmed et al. 2002), a second item was used in this case, "willingness to try", to help enhance the robustness of the analysis and confidence in the findings. In total, 14 items were used to evaluate each of the countries under investigation (7 PRO, 7 C+P, 2 LTP).

Animosity (ANI). The animosity scale was adapted from the work of Klein, Ettenson, and Morris (1998), which has been validated in several studies (e.g., Huang, Phau, and Lin 2010). Nonetheless, as noted by Riefler and Diamantopoulos (2007), it is important to not just adopt previously-used scales "as-is" but to adjust them so as to reflect the specifics of the situation at hand. In their "beyond anger" study, Harmeling, Magnusson, and Singh (2015) have examined the "emotional core" of the animosity construct and found that different negative emotions (anger or contempt vs. retreat or insecurity) may lead to distinct cognitive and behavioural reactions (e.g., quality judgement vs. product avoidance). In this study, the animosity scale consisted of five items common to all three target countries, but also included items that would not make sense if asked in all cases (e.g., for Egyptian-origin Canadians "anger" and/or "forgiveness" make sense in relation to Israel but not Brazil or Tunisia); as a result, two items were added only for Tunisia and Brazil and six only for Israel. 
Affinity $(A F F)$. The study used seven items adapted from the only extant scale to measure consumer affinity, proposed by Oberecker and Diamantopoulos (2011), which includes measures for friendliness, the feelings evoked when one thinks of the target country, and its similarity to one's home culture.

\section{DATA ANALYSIS AND RESULTS}

The analysis was carried out in three main parts intended to explore the data and test the hypotheses. These included Multiple Analysis of Variance (MANOVA), to examine and contrast the respondents' attitudes to the target countries; Exploratory Factor Analysis (EFA), which makes it possible to examine and contrast the structure of consumer thoughts about the target countries as well as to construct the composite variables needed for the next stage in the analysis; and stepwise multiple regression, to study the predictive ability of the variables and their relative importance in influencing likelihood to purchase.

\section{Attitudes to Countries/People and Products}

Repeated within-subjects MANOVA was used to test for differences in attitudes toward the three countries. All the MANOVA models were highly significant at 0.001 , and, consistent with earlier PCI studies and as suggested by Stevens (2002), the alpha accepted for significance in post-hoc tests was adjusted to 0.001 .

The pairwise comparisons of the mean responses for the product and country/people variables are presented in Table 1. Table 1.a., which deals with assessments of the countries' products, shows that significant differences were observed between Israel, on the one hand, and Tunisia and Brazil, on the other, on six variables, including cognitive (technically advanced, innovative, value), affective (proud to own) and conative (willingness to try, willingness to buy) items, with the most significant difference found for "proud to own." Additionally, as shown in 
Table 1.b., significant differences were found for Israel by comparison to the other two countries across all country/people variables except for "politically stable", where the ratings for Israel and Tunisia were similar. The affective variables "ideal country" and "likeable people" showed the most significant differences in this scale.

\section{Table 1 about here}

Some of the baseline data from this part of the analysis might be deemed to have been predictable, but they are much more nuanced than initially meets the eye. More importantly, their value lies in enabling the cross-country comparison, where they are necessary and critical to reexamining and challenging some of the basic assumptions that are inherent in single-country animosity or affinity studies. Specifically, in line with expectations from affinity theory, several differences were observed between Tunisia and Brazil in Table 1.b., where the "affinity" country was evaluated less positively on political stability but significantly higher on "trustworthiness" and "likeability". By contrast, there were no significant differences in product means (Table 1.a.) between Brazil and Tunisia except on "innovativeness". This is surprising especially with regards to the "proud to own" and "willingness to try/buy" items, where affinity theory would suggest that Tunisia would have been rated significantly higher, especially since respondents did not see any difference in the quality and technical advancement of these countries' products.

Turning to Israel, the "animosity" country, the findings are closer to expectation overall but still point to several nuanced insights. It is clear that respondents recognize the superiority of Israeli technology and innovativeness (Table 1.a.) and standard of living (Table 1.b.) over both Tunisia and Brazil, while at the same time rating Israel lower than, and most often the lowest of, the other two countries on most dimensions, in both the product and country/people groups. However, closer examination of the individual variables suggests that in absolute terms some of the measures are surprising. For instance, Tunisia scores barely above the mid-point of the scale 
on pride of ownership of its products (mean of 4.2); both it and Brazil are rated below the midpoint as "ideal countries"; and Israel's rating on product satisfaction is not statistically different from those of the other two countries.

These findings provide only partial support for the first two hypotheses, H1a and H1b. The data suggest that respondents are pragmatic in their purchase intentions and overall attitudes, while also indicating strong affective reactions in some cases and weaker ones in others, often challenging precepts from extant research. Generally, Israel scored the highest on the more "objective" variables but was the lowest on affect (e.g., pride in ownership, ideal country). While Tunisia is evaluated positively on some measures, its weaknesses in such cases as pride in ownership, ideal country, and willingness to buy, both in absolute terms and, especially, when compared to the benchmark country, are apparent.

The analysis for the five animosity variables that were asked for all three countries (Table 2.a.) also produced several interesting insights. As anticipated, Tunisia and Brazil are rated significantly lower than Israel on all animosity variables, which lies near the top of the scale. However, the pairwise Brazil-Tunisia comparisons show no significant differences for any scale item. This is interesting in two ways similar to those discussed just above for the PRO and $\mathrm{C}+\mathrm{P}$ ratings. The first points to one of the advantages of testing for both affinity and animosity at the same time. Each has used entirely different scales, even though many of those used for one could be "flipped" and used for the other - e.g., strong agreement with "I dislike [animosity country]" is equivalent to strong disagreement with "I like [affinity country]". Thus it might have been expected that the affinity country would have been rated significantly lower than the benchmark on animosity. Yet while the differences in means are in the right direction, none is significant. The second point of interest is that, while statistically different from those for Israel, some of the animosity means for Tunisia and Brazil are relatively higher in absolute terms than might have 
been expected. As with the weak rating on "proud to own", both Tunisia and Brazil have means in the 3.0 range on the "trade" and "doing business" measures, which suggests at least some level of respondent dissatisfaction. Taking the above into account, H2a, which posits a clear animositybenchmark-affinity country distinction, is supported only for the animosity-to-other comparison.

\section{Table 2 about here}

The MANOVA outcomes on affinity (Table 2.b.) also showed highly significant differences across all three countries, and in this case the results are much clearer than in the scales discussed above. With only one exception where Brazil and Tunisia were rated equally, the affinity country is rated significantly higher, with the animosity country significantly lower and the benchmark country in-between, in all cases. Further, there are no ratings "on the margin" in absolute terms, with all Tunisian ratings being the highest, all Israeli ratings the lowest, and allbut-one of Brazil's in-between. Therefore, for the first time in this analysis, this generates a clear image in line with expectation, as posited in $\mathrm{H} 2 \mathrm{~b}$.

\section{Data Structure}

Principal Components Analysis (PCA) was used for the factor analysis of each scale. Significant factors were identified using the screeplot, the eigenvalue criterion of $>1$, and promax rotation. The retention of items for each factor was based on item loadings of 0.40 or higher (Osborne and Costello 2004), and in the case of cross-loadings the items with the higher loadings were retained for the analysis (Worthington and Whittaker 2006). Scale reliability was assessed by Cronbach's alpha, where overall $\alpha>0.70$ indicates satisfactory internal consistency, while an $\alpha>0.60$ is also considered acceptable and commonly used on predictor tests and hypothesized measures in studies where prior theory is not yet well developed (Shay and Baack 2004), as is the case here.

Product Evaluations (PRO). Two factors are consistent across the three countries, albeit with a few minor, yet potentially important, differences (Table 3.a.). The first (PRO-1) includes 
the quality and value-for-money items for the three countries, echoing the value perception of their products. The second (PRO-2) reflects technical advancement and innovativeness, with these two variables loading here in all cases. Pride in ownership loaded with "development" for Brazil but "value" for Tunisia, signalling the subjects' attachment to the affinity country, and did not appear for Israel. Conversely, satisfaction did not appear for Tunisia or Brazil but loaded with "development" for Israel, thus tying this variable to the country's previously-noted higher ratings for technology and innovativeness. The reliability coefficients for PRO-1 and PRO-2 were above 0.60, with the exception of a surprisingly low alpha for PRO-2 in the case of Brazil. Drawing on Worthington and Whittaker (2006), who note that decisions on which items or factors to retain or delete may be made on the basis of theory, logic, and past research findings, it was decided to retain all the other factors, which are supported by earlier studies (e.g., Papadopoulos, Heslop, and IKON 2000), but to drop PRO-2 from further analysis in the case of Brazil.

\section{Table 3 about here}

Country and People $(C+P)$. As with the product components, the structure of consumer thoughts is also consistent across the three countries (Table 3.b.). The first factor, which splits into two for Tunisia, consists mainly of affect variables that refer to liking of a country and its people. Technology also loads highly on this factor for Tunisia and Brazil, suggesting that it contributes to the overall positive perception of both countries, while for Israel it appears separately in a single-item factor, possibly because for this country this is seen as an entirely different issue from broader like/dislike considerations. The second factor encapsulates, and relates, the countries' standard of living and level of political stability. The internal consistency of the country/people scale was not strong, with one-half of the reliability coefficients being above, and one-half below, the .60 cutoff. Nevertheless, it seems worth noting that the development factor was identical in composition across the three countries, showing consistency in the 
respondents' mental schemata of the countries' images and signalling a positive correlation between political stability and a high standard of living.

Animosity (ANI). The PCA yielded highly consistent results when the similarities and differences among the target countries, and the differences in the scales used for Israel versus Tunisia and Brazil, are taken into account (Table 4.a.). The reliability coefficients were strong (0.75 to 0.86$)$, indicating high internal consistency in the animosity factors. The structure for Israel has both similarities and differences from those of Tunisia and Brazil. The first factor clearly is unique to Israel and consists of the variables not asked for Tunisia or Brazil. All five of these variables appear together in a single factor that explains $48.72 \%$ of the variance. This reflects the dimensions of "war animosity" toward Israel and subsumes the negative feelings formed after decades of an unsettled state of affairs between it and the respondents' ethnic home country. This factor also includes product-related variables for Israel, indicating that marketplace actions are strongly related with negative feelings of war animosity. The second factor, "trade" animosity, contains the business variables that are part of this factor for Tunisia and Brazil as well as those reflecting the dislike of the target country and its people. Thus the intense feelings of dislike toward Israel are correlated not just with specific market-related consumer actions (since product ownership variables loaded on the previous factor) but also with the broader notion of doing any business at all with that country and its people. Interestingly, the "forgiveness" variable also loads here, which may suggest that forgiving Israel for its past actions may not necessarily mean wanting to do business with them. The factor structures for the other two countries were identical. The first factor reflects feelings toward the affinity and benchmark countries, their people, and their products, and is tied mostly to their political stance (or lack thereof) toward the subjects' original homeland. The second factor is a "call for caution" when doing business with the countries and their people. 


\section{$\underline{\text { Table } 4 \text { about here }}$}

Affinity $(A F F)$. Following the same pattern as with the previous scales, the factor structures for Tunisia and Brazil are identical on the affinity construct, with all variables combining into a single factor with strong reliability measures and item loadings (Table 4.b.). Two factors emerged for Brazil, of which the first is very similar to the corresponding single factors for the other two countries. The second factor (with a barely marginal Cronbach's alpha at .60) contains the cultural similarity and attachment variables and is unique to Brazil, as might be expected since this country was selected for being "neutral" to the Egypt-Israel-Tunisia triangle.

Conclusions from PCA. Taking together the outcomes for the four constructs, and with due attention to the differences in animosity for Israel versus Brazil and Tunisia, the PCA analysis supports $\mathrm{H} 3$, which posited that the consumers' mental schemata would be similar across the three countries. Since these schemata are also consistent with prior research, this increases confidence in using the emerged factor structure as the base for the next stage of the analysis.

\section{Relative Importance of Predictor Variables}

Stepwise regression was used to examine the potential predictors of Likelihood to Purchase (LTP) the countries' products. As highlighted by Yaprak (2008, p. 224), in the search for variables that best explain variation in the data, procedures such as stepwise regression "allow delineation of spurious correlation among the dimensions, so that the independent effects of dimensions can be observed more clearly for a better interpretation of findings". The variables used in this analysis were operationalized based on the outcomes of the PCA discussed above. Factors with an acceptable reliability coefficient of 0.70 or higher, with only a few exceptions (4 out of 20 instances) at $>0.60$, were retained for further analysis and used to operationalize the study's constructs as multi-item composite measures. The structure of the variables and their corresponding alpha values are shown in Table 5. 


\section{$\underline{\text { Table } 5 \text { about here }}$}

A sequential analysis was carried out to assess the relative importance of the predictive ability of the six product-country dimensions, namely, Product Evaluations (PRO-1 and PRO-2) Country and People $(C+P)$ Evaluations, Animosity (ANI-1 and ANI-2), and Affinity (AFF), on Likelihood to Purchase (LTP) the target countries' products. Conclusions regarding a predictor's contribution are most appropriate, and are often of interest in research, when there are no theoretical suggestions concerning the order of the predictor variables relative to the study's outcome (Yaprak 2008), as is the case here. Using stepwise regression, the six predictors were entered one at a time, separately for each country, with the effect of the other predictors partialled out or held constant, in accounting for the variance in the independent variable (Stevens 2002). The model guiding the analysis is shown in Figure 2, and the results are presented in Table 6.

\section{Figure 2 and Table 6 about here}

$\mathrm{H} 4 \mathrm{a}$ and $\mathrm{H} 4 \mathrm{~b}$ (Table 6.a.) posit that higher country/people and product evaluations will enhance the receptivity of a country's products. However, the $\mathrm{C}+\mathrm{P}$ component accounts for significant changes only in the LTP for products from Israel. This may suggest that, for ethnic consumers, the image of a country and its people matters most when it comes to an animosity country, whereas it may not have a significant effect on countries toward which the consumer already has positive or neutral feelings. Therefore, H4a is rejected. Concerning the product scale, the first component (PRO-1, "value") returned significant coefficients for all countries, but the second (PRO-2, "development") was a significant LTP predictor for Israel only. Therefore, the analysis confirms the perceived value of products from a given country as an important predictor of their receptivity, but not that of development level, leading to partial support for H4b.

$\mathrm{H} 4 \mathrm{c}$ and $\mathrm{H} 4 \mathrm{~d}$ refer to the potential effects of affinity and animosity. Table 6.a. shows that ANI-1 (general or war/political animosity) did not appear as a predictor for Brazil and Tunisia 
but returned a significant negative coefficient for LTP, and accounted for the most variability in purchase intent, for products from the animosity country. ANI-2 (trade animosity) did not appear as a significant predictor for any of the three countries. Therefore, $\mathrm{H} 4 \mathrm{c}$ is supported only with regards to animosity reflecting war/political concerns. Turning to affinity, it did not appear for Israel but was a robust predictor of LTP for Tunisia and Brazil. This is in line with expectations for Tunisia, selected as the affinity country, but not necessarily for the "neutral" country, for which there was no readily observable reason to suspect "special liking" on the part of the respondents. Therefore, H4d is also supported only partially.

Finally, hypotheses $\mathrm{H} 4 \mathrm{e}, \mathrm{H} 4 \mathrm{f}$, and $\mathrm{H} 4 \mathrm{~g}$, which examine the relative importance of the four constructs as predictors of LTP, are not supported by the data. While animosity does appear as the predominant explanator of LTP for Israel (H4e), affinity appears not only for Tunisia but also for Brazil (H4f), the country/people construct appears only for Israel, and the specific sequencing of constructs that was put forth in these three hypotheses did not materialize for any of the countries. Therefore, these hypotheses are rejected.

\section{DISCUSSION AND IMPLICATIONS}

While in earlier times consumer ethnicity might have been deemed relevant only to traditionally multicultural countries, global mobility and the rise of multiculturalism worldwide have made it a matter of intense interest to many more countries from both the theory and managerial perspectives. As noted by Berking (2003, p. 248), "the 'national' is increasingly losing its significance as the master frame". If anything, the recent mass migration waves around the world exacerbate the importance of the issue and make it a sine qua non for consideration among both researchers and practitioners. The present study contributes by focusing attention on ethnic consumers and examining the "old country passions" that may arise from their links to their 
original homeland, considering simultaneously the interrelationships among, and impacts of, the country/people image, product image, animosity, and affinity constructs. This leads to a variety of theoretical and managerial implications, which are discussed below.

\section{Theoretical Implications}

Viewed by themselves, the animosity and affinity results were as might have been anticipated in some respects and leave little doubt as to whom these respondents like and do not like. Living in Canada, which is on good terms with all the countries in this study, coupled with the respondents' potential acculturation to it as the host country, have not resulted in dimming "old country passions". At the same time, the findings are highly nuanced and provide considerable new insights, especially when contrasted to those from the other two constructs in the study, and the similarity in data structure across the three countries and by comparison to previous research, as indicated by the factor analysis, enhances confidence in interpreting the results.

Israel scores the highest on animosity, but, with means at around 3.0 on their reliability as trade partners, Tunisia and Brazil are also subject to feelings that are not as positive as might have been expected based on past animosity research. Coupled with the product evaluations (Table 1.a.), which, notwithstanding affinity theory, show Tunisia and Brazil on an equal footing with only one significant difference over nine variables, this casts doubt on the relevance of affinity in product assessments as measured by well-established product image scales. Particularly noteworthy is the lack of significant differences between these two countries on the "willingness to try/buy" variables, and even more so on "proud to own", where, according to PCI theory, affect would have been expected to result in a significant difference favouring Tunisia over Brazil regardless of the related cognitive evaluations.

The country/people scale (Table 1.b.) suggests a distinction between the measures for country advancement and people affect, where, respectively, each of Brazil and Tunisia are rated 
more highly than the other - and yet Tunisia clearly is the "affinity favourite" in the affinity scale (Table 2.b.). It is important to recall here that, similarly to animosity, affinity uses measures that are different from the country/people scales typically used in mainline PCI research. This is an important finding that highlights the intended contribution of this study: had Tunisia been the only research object in a single-country affinity study, its affinity ratings might have led to a conclusion that an "affinity effect" was at work - a conclusion that is challenged by the product and country/people image scales drawn from the broader theory of PCI effects. The juxtaposition of these findings, made possible by the simultaneous examination of the relevant measures, suggests that the affinity construct may be more complex than previously thought and that its relationship with country/people and product scales (what Oberecker and Diamantopoulos (2011) refer to as a country's "macro" and "micro" images) needs to be re-examined.

The study suggests that consumers withhold their negative feelings from product judgements only when the latter involve technical features, as is the case with Israel's high ratings on technology and innovativeness. Critical attitudes do surface on affective criteria expressed with emotion-laden phrases included in the present study, such as "proud to own", which combined general PCI, affinity, and animosity constructs, but not in extant single-construct research. These findings also conform with research that shows that emotion has a stronger effect on behaviour when "affective-cognitive ambivalence exists" (Lavine et al. 1998, p. 402) and may have a more immediate impact on purchase intentions (Harmeling, Magnusson, and Singh 2015).

This study included several different measures of affect in all four construct scales, but only the war/political component of animosity emerged as a significant driver of LTP in one case (Israel); affinity did not differentiate purchase intentions between the affinity and benchmark countries; and the country/people measures also did not predict purchase intent except, again, for Israel. These findings are in line with research in other areas of the social sciences, which 
suggests that negative feelings toward outgroups tend to be stronger, more likely to be articulated outwardly, and to have a stronger impact on behaviour, than positive ones toward ingroups (e.g., Russel and Carroll 1999; Wohl, Branscombe, and Klar 2006). Furthermore, negative feelings related to the reliability of a country as a trade and business partner were not a significant predictor of LTP for Israel, even though the dislike of the country and its people appeared as part of the same consumer mental schema in the factor analysis. Therefore, as noted by Harmeling, Magnusson, and Singh (2015), if researchers were to draw accurate assumptions about the structure of the animosity construct and its impact on purchase intentions, they need to further examine its "emotional core" - and the same can be said for affinity, which is also an emotionladen construct (Oberecker and Diamantopoulos 2011).

Consistent with the conceptualization of affinity, it was expected that it would be expressed specifically toward Tunisia. However, the product component turned out to be a more significant predictor of LTP, which contradicts previous findings that affinity, like animosity, will affect behaviour regardless of product beliefs. Moreover, recent research suggests that one may develop affinity toward a foreign country based either on identification with its culture or on attractiveness to social place elements that relate to one's social identity (Nes, Yelkur, and Silkoset 2014). Affinity toward Brazil cannot be explained by reference to cultural similarity, since that country is quite unlike the respondents' home country in all respects. However, other potentially relevant constructs, such as "sports affinity" (Hough 2008), might raise the possibility of a connection between Brazil's reputation and Egypt's passion for soccer (Al Aswany 2014). An alternative explanation might be that the relative importance of affinity toward Brazil may reflect a sort of cosmopolitanism, which is associated with the construction of multiple place allegiances (Cleveland, Laroche, and Papadopoulos 2009; Balabanis and Diamantopoulos 2016) and "might be an affinity for the best of everything" (Cannon and Yaprak 2002, p. 45). This view of affinity 
can also be examined under the context of consumer xenocentrism, which refers to a general preference of foreign products (Balabanis and Diamantopoulos 2016).

Such thoughts buttress the suggestion that the conceptualization of affinity and animosity may need to be reconsidered, as should their relationship to the principal country/people image and product image constructs. Moreover, they also underscore the contribution of this study in including a benchmark country, since the presence of such countries in future study designs may help to uncover relationships that have not been attended to until now.

More broadly, the study's findings suggest that there is value to examining animosity and affinity together and for three (or more) countries. Responses to animosity or affinity studies, each using different measures applied to different countries, may mean little or nothing, and may even be misleading, if the same measures might have yielded similar responses for another country(ies) that was not included in the study. Similarly, a study using "animosity" measures to study "animosity" only may miss out on the affective dimensions that may be revealed through the simultaneous use of affinity measures.

As noted earlier, some of the findings may appear predictable at first glance but are much more nuanced when examined more closely. That the ratings for Israel are significantly higher or lower on a given measure than those for Tunisia and/or Brazil in the post-hoc MANOVA tests may be interesting as a comparative measure, but (a) without the affinity and benchmark countries, in themselves those ratings might not have meant much; and (b) viewed in absolute terms the same measures may lead to different conclusions for one or another country. Affinity and animosity may be partly or entirely different constructs, or they may be the "mirror-image" or obverse of each other as we noted in the introduction, leading to different theoretical and methodological implications in each case. Respectively, each construct may need to be conceptualized and measured as distinct from the other, or perhaps a carefully developed single 
scale may be sufficient for measuring both constructs, reflecting a continuum where the presence of one would mean the absence of the other. Whichever the case may be, only further study of both constructs concurrently, for three or more countries, will help to shed further light on the inter-relationships, if any, between them.

\section{Managerial Implications}

The phenomenon of immigrants maintaining ties with their home countries, creating in their host countries neighbourhoods or entire city sections that are miniature replicas of their former ethnic environments, raising their children based on "like home" precepts, and trading products and services tailored to their ethnic preferences, is common across ethnic communities (e.g., Johansson and Cornebise 2010). Recent large scale migrations, such as those from Asia and East Europe to the UK, have changed the socio-economic environment of several cities and resulted in new communities with strong ties to their home countries (Doughty 2013), thus further increasing the importance of ethnic consumers. Understanding the ethnic fabric of a country, and examining ethnic consumers' characteristics and needs as buyers in depth, is essential to developing the right marketing strategies that can impact product evaluations and buying intentions.

For practitioners and policy makers the findings highlight the significant role of country image in influencing consumers, and offer international marketing managers an opportunity to understand complex country-product related behaviours. For instance, while $\mathrm{C}+\mathrm{P}$ evaluations of the affinity and neutral countries were greatly associated in the minds of consumers with both "affect" and "technological advancement", the later appeared as a single factor item, signalling no correlation between it and the liking or disliking of the country. This finding can guide marketing managers on which aspects of a country, regardless of its affiliation with the ethnic consumer's home, can have un/favourable effects on its overall evaluations, pointing in this case to the potential benefits of highlighting technological superiority in marketing campaigns. 
The tendency of ethnic consumers to look for products "from home" has been researched extensively - but the extension of feelings of like or dislike toward other countries that may be positively or negatively associated with home had not prior to the present study. Understanding the components of animosity or affinity, and how these can affect purchase intentions in relation to which country(ies), is essential. For instance, the findings show that war animosity can be stronger in predicting purchase intent than affinity, but also that affinity may extend beyond cultural proximity and include other countries that may be perceived as generally "neutral" or share something as simple as a passion for soccer. Knowing the drivers of affinity can also help managers uncover the elements that heighten ethnic consumers' positive feelings toward countries that are not directly linked to their home countries, capitalize on consumers "soft" spots for countries and people, and understand the impact all this has on product evaluations. Taking up an example cited earlier, corporate sports sponsorship associated with a specific country can be one way to elicit affinity feelings from ethnic groups that have a passion for the sport.

Notwithstanding the complexity of unravelling the interplay between country/people, product, animosity, and affinity constructs in research, for managers this study provides a variety of insights that can translate to concrete marketplace actions. For example, to lessen/enhance the impact of negative/positive feelings toward countries linked to the ethnic consumer's home, marketers may consider co-branding to leverage brands that enhance affinity or mitigate animosity associations. The relative power of affinity and product image in the cases of Brazil and Tunisia suggests that, notwithstanding different findings in PCI research, at least some firms may be able to "bypass" elements of the country/people construct (which did not seem to be activated except in the case of Israel) and focus strongly or exclusively on affective content (which emerges as a key explanator, albeit in different guises, for all countries) in their marketing strategies. Stated differently, strategies designed to elicit affinity emotions while minimizing 
negative affect may help to 'sell products by tugging directly on ethnic consumers' heartstrings'. Finally, the factor analysis, strengthened by the similarity of structure across the three countries and with extant theory, points to the mental schemata that predominate in ethnic consumers' minds and can be used to configure advertising and other marketing mix strategies.

\section{LIMITATIONS AND FUTURE RESEARCH DIRECTIONS}

The study examines only one specific ethnic group, and does so through a mixed-method approach which may produce method-based differences (although in this case, as reported above, it did not). Therefore, replications across different contexts, perhaps using a single method if enough respondents can be identified for it, can help to validate, augment, or question its findings and conclusions about bicultural ethnic consumers. The variables chosen for operationalizing the constructs have been tested before and were appropriate in the context of this study, but some did not work well in some cases (e.g., PRO-2 for Brazil). More importantly, the interplay of findings between the $\mathrm{C}+\mathrm{P}, \mathrm{ANI}$, and AFF scales was surprising in several cases and occasionally conflicted with theoretical precepts in one or more of these areas. Therefore, additional testing can only add value to the current results.

Further, mindful of questionnaire length as well as the need to focus on the principal constructs of interest, this study opted for parsimony in how many and which concepts/constructs to include in the survey and then to analyze. Future studies, particularly if well-resourced, may be able to include additional constructs that appear in the broader PCI literature, such as cosmopolitanism, and to examine relationships both among the four constructs included here as well as between them and others that may be added.

The study took "global" measures of the target countries' products, people, and the countries themselves, instead of product-, people-, or area-specific measures. Past research has 
demonstrated that positive or negative country associations and their effects are evident for both products in general as well as specific product categories, and that global and category-specific measures tend to move in the same direction (e.g., Laroche et al. 2005; Shoham et al. 2006). Therefore, given the innovative nature of the present study and its focus simultaneously on the overall relationships between PCI, animosity, affinity, and LTP, global measures were deemed appropriate in this case. Nevertheless, future category-specific research, though by definition limited in generalizability, can contribute by developing insights on the constructs within specific product or other categories (tourism for "country X" versus specific destinations within it).

Finally, as Pires, Stanton, and Cheek (2003) and many others have stressed, ethnicity is a very complex social construction. If anything, this complexity has increased with the current growth in consumer mobility and immigration. While the focus of this study did not make it possible to examine ethnicity in depth, new studies focusing on ethnic consumer behaviour in different settings would represent a very fruitful direction for future research. The selection of the "right" ethnic groups must take a number of factors into account, along the lines of those used here. On the other hand, it may also include a potential shift of focus from the traditional "multicultural laboratories" for ethnic research, such as Canada, to countries where the immigration phenomenon is newer and targeting emigrants who live away from their home country is becoming more important by the day (Kumar and Steenkamp 2013).

In conclusion, this study focused on four interrelated constructs and produced results that in some ways agree with and enhance, and in some others challenge, existing methodological approaches and extant theory in PCI, animosity, and affinity research. Future studies would stand to benefit greatly by research that focuses on delineating the conceptual boundaries of the relevant constructs, and that use three or more countries for analysis so as to make it possible to benchmark the findings from the measures used. 


\section{REFERENCES}

Ahmed, Zafar U., James P. Johnson, Chew Pei Ling, Tan Wai Fang, and Hui, Ang Kah Hui (2002), "Country-of-origin and brand effects on consumers' evaluations of cruise lines," International Marketing Review, 19 (3), 279-302.

Ajzen, Icek (1989), "Attitude Structure and Behavior", in Attitude Structure and Function, A.R. Pratkanis, S.J. Breckler, and A.G. Greenwald, eds. Hillsdale, NJ: Lawrence Erlbaum Associates, 241-274.

Al Aswany, Alaa (2014), "Egypt's Enduring Passion for Soccer," The New York Times, April 16, www.nytimes.com/2014/04/17/opinion/egypts-enduring-passion-for-soccer.html?_r=0; accessed November 5, 2015.

Amine, Lynn S., Mike C.H. Chao, and Mark J. Arnold (2005), "Exploring the Practical Effects of Country of Origin, Animosity, and Price-Quality Issues: Two Case Studies of Taiwan and Acer in China," Journal of International Marketing, 13 (2), 114-150.

Bagozzi, Richard P., Alice M. Tybout, C. Samuel Craig, and Brian Sternthal (1979), "The construct validity of the tripartite classifications of attitudes, " Journal of Marketing, 16 (1), 8895.

Balabanis, George, and Adamantios Diamantopoulos (2016), "Consumer Xenocentrism as Determinant of Foreign Product Preference: A System Justification Perspective, " Journal of International Marketing, 24 (3), 58-77. 
Barhouma, Moussa (2014), "Comparing the Tunisian, Egyptian revolutions," Al Monitor, February 17, www.al-monitor.com/pulse/politics/2014/02/egypt-tunisia-revolutioncomparison.html; accessed October 23, 2016.

Berking, Helmuth (2003), "'Ethnicity is everywhere': on globalization and the transformation of cultural identity," Current Sociology, 51 (3-4), 248-264.

Bicchi, Federica (2011), "The Union for the Mediterranean, or the Changing Context of EuroMediterranean Relations?," Mediterranean Politics, 16 (1), 3-19.

Burton, Dawn (2000), "Ethnicity, Identity, and Marketing: A Critical Review," Journal of Marketing Management, 16 (8), 853-877.

Butler, Kim D. (2001), "Defining Diaspora, Refining a Discourse," Diaspora: A Journal of Transnational Studies, 10 (2), 189-219.

Cannon, Hugh M., and Attila Yaprak (2002), "Will the real-world citizen please stand up! The many faces of cosmopolitan consumer behavior, "Journal of International Marketing, 10 (4), 3052.

Cleveland, Mark, and Michel Laroche (2007), "Acculturation to the Global Consumer Culture: Scale Development and Research Paradigm," Journal of Business Research, 60 (3), 249-259. 
Cleveland, Mark, Michel Laroche, Frank Pons, and Rony Kastoun (2009), "Acculturation and consumption: Textures of cultural adaptation," International Journal of Intercultural Relations, $33(3), 196-212$.

Cleveland, Mark, Michel Laroche, and Nicolas Papadopoulos (2009), "Cosmopolitanism, consumer ethnocentrism, and materialism: an eight-country study of antecedents and outcomes," Journal of International Marketing, 17 (1), 116-146.

Cui, Geng (2001), "Marketing to ethnic minority consumers: a historical journey (1932-1997)," Journal of Macromarketing, 21 (1), 23-31.

Daily News Egypt (2016), "Egyptian-Tunisian brotherhood week," www.dailynewsegypt.com/2016/09/07/egyptian-tunisian-brotherhood-week-begins-enrichingcultural-exchange-two-countries/, September 7; accessed October 14, 2016.

Doughty, Steve (2013), "White Britons are now a minority in Leicester, Luton and Slough and Birmingham is set to follow by end of decade," The Daily Mail, http://www.dailymail.co.uk/news/article-2260067/White-Britons-minority-Leicester-LutonSlough-Birmingham-set-follow-end-decade.html, January 10; accessed February 13, 2017.

Duruz, Jean (2000), "A Nice Baked Dinner...or Two Roast Ducks from Chinatown?: Identity grazing," Continuum: Journal of Media and Cultural Studies, 14:3, 289-301. 
Eagly, Alice H., and Shelly Chaiken (1993), The Psychology of Attitudes. Orlando, FL: Harcourt Brace Jovanovich.

Hamlett, Jane, Adrian R. Bailey, Andrew Alexander, and Gareth Shaw (2008), "Ethnicity and consumption : South Asian food shopping patterns in Britain 1947-75," Journal of Consumer Culture, 8 (1), 91-116.

Hamzaoui-Essoussi, Leila, Dwight Merunka, and Boris Bartikowski (2011), "Brand origin and country of manufacture influences on brand equity and the moderating role of brand typicality," Journal of Business Research, 64 (9), 973-978.

Harmeling, Colleen M. Peter Magnusson, and Nitish Singh (2015), "Beyond anger: A deeper look at consumer animosity," Journal of International Business Studies, 46 (6), 676-693.

Heinbecker, Paul, and Bessma Momani (2010), Canada and the Middle East: In theory and practice. Waterloo, ON: Wilfrid Laurier University Press.

Heslop, Louse A., Irene R. Lu, and David Cray (2009), "Australian consumers' attitudes toward France a decade after nuclear testing: evidence of forgiveness, " Journal of Consumer Behaviour, $8(4), 192-210$.

Heslop, Louise A., Nicolas Papadopoulos, and Margie Bourk (1998), "An interregional and intercultural perspective on subcultural differences in product evaluations," Canadian Journal of Administrative Sciences, 15 (2), 113-126. 
Hough, Peter (2008), "'Make Goals Not War': The Contribution of International Football to World Peace," International Journal of the History of Sport, 25 (10), 1287-1305.

Huang, Yu-An, Ian Phau, and Chad Lin (2010), "Effects of animosity and allocentrism on consumer ethnocentrism: Social identity on consumer willingness to purchase," Asia Pacific Management Review, 15 (3), 359-376.

Huitzilin Jiménez, Nadia, and Sonia San Martín (2010), "The role of country-of-origin, ethnocentrism and animosity in promoting consumer trust. The moderating role of familiarity," International Business Review, 19 (1), 34-45.

Jafari, Aliakbar., and Luca M. Visconti (2015), "New directions in researching ethnicity in marketing and consumer behavior: A well-being agenda," Marketing Theory, 15 (2), 265-270.

Johansson, Ola. and Michael Cornebise (2010), "Place Branding Goes to the Neighborhood: The Case of Pseudo-Swedish Andersonville," Geografiska Annaler B: Human Geography, 92 (3), $187-204$.

Kazarian, Shahe S., and Maral D. Boyadjian (2008), "Validation of the Multigroup Ethnic Identity Measure Among Ethnic Armenian Adolescents in Lebanon," Identity: An International Journal of Theory and Research, 8 (4), 335-347. 
Kim, Young Yun (2008), "Intercultural personhood: Globalization and a way of being," International Journal of Intercultural Relations, 32 (4), 359-368.

Klein, Jill Gabrielle (2002), "Us Versus Them, or Us Versus Everyone? Delineating Consumer Aversion to Foreign Goods," Journal of International Business Studies, 33 (2), 345-363.

Klein, Jill Gabrielle, Richard Ettenson, and Marlene D. Morris (1998), "The animosity model of foreign product purchase: An empirical test in the People's Republic of China," Journal of Marketing, 62 (2), 89-100.

Knight, Gary A., and Roger J. Calantone (2000), "A flexible model of consumer country-oforigin perceptions, " International Marketing Review, 17 (2), 127-145.

Kumar, Nirmalya, and Jan-Benedict E.M. Steenkamp (2013), "Diaspora marketing," Harvard Business Review, 91 (10), 127-132.

Lee, You-Kyung, and Charles Arthur Robb (2016), "Moderating Effect of Country Familiarity and Country Image on Product Purchase Intention in South Africa, "Journal of International Trade \& Commerce, 12 (4), 237-256.

Laroche, Michel, Nicolas Papadopoulos, Louise A. Heslop, and Mehdi Mourali (2005), "The influence of country image structure on consumer evaluations of foreign products, "International Marketing Review, 22 (1), 96-115. 
Las Casas, Alexandre Luzzi, and Ana Paula Maiochi Silverio (2015), "Strategic image management: The image of the City of So Paulo/SP," African Journal of Business Management, 9 (6), 288-297.

Lavine, Howard, Cynthia J. Thomsen, Mark P. Zanna, and Eugene Borgida (1998), "On the primacy of affect in the determination of attitudes and behavior: the moderating role of affectivecognitive ambivalence, " Journal of Experimental Social Psychology, 34 (4), 398-421.

Leahy, Rose (2011), "Relationships in fast moving consumer goods markets: The consumers' perspective," European Journal of Marketing, 45 (4), 651-672.

Lee, Moonkyu, and Yung-Chien Lou (2011), "Consumer reliance on intrinsic and extrinsic cues in product evaluations: a conjoint approach, " Journal of Applied Business Research, 12 (1), 2129.

Leong, Siew Meng, Joseph A. Cote, Swee Hoon Ang, Soo Jiuan Tan, Kwon Jung, Ah Keng Kau, and Chanthika Pornpitakpan (2008), "Understanding consumer animosity in an international crisis: nature, antecedents, and consequences, " Journal of International Business Studies, 39 (6), 996-1009.

Li, Dongjin, Cheng Lu Wang, Ying Jiang, Bradleyh R. Barnes, and Hao Zhang (2014), "The asymmetric influence of cognitive and affective country image on rational and experiential purchases," European Journal of Marketing, 48 (11/12), 2153-2175. 
Lindridge, Andrew (2010), "Are we fooling ourselves when we talk about ethnic homogeneity? The case of religion and ethnic subdivisions amongst Indians living in Britain, " Journal of Marketing Management, 26 (5-6), 441-472.

Little, Joseph P., and Nitish Singh (2014), "An exploratory study of Anglo-American consumer animosity toward the use of the Spanish language, " Journal of Marketing Theory and Practice, $22(3), 315-324$.

Macrae, C. Neil, and Susanne Quadflieg (2010), "Perceiving people," in Handbook of social psychology, $5^{\text {th }}$ ed., V. 1, S.T. Fiske, D.T. Gilbert, and G. Lindzey, eds. Hoboken, NJ: Wiley, 428-463.

Martin, Ingrid M. and Sevgin A. Eroglu (1993), "Measuring a Multi-Dimensional Construct: Country Image," Journal of Business Research, 28 (3), 191-210.

Nes, Erik Bertin, Rama Yelkur, and Ragnhild Silkoset (2014), "Consumer affinity for foreign countries: Construct development, buying behavior consequences and animosity contrasts," International Business Review, 23 (4), 774-784.

Nijssen, Edwin J., and Susan P. Douglas (2004), "Examining the animosity model in a country with a high level of foreign trade, " International Journal of Research in Marketing, 21 (1), 23-38. 
Oberecker, Eva M., and Adamantios Diamantopoulos (2011), "Consumers' emotional bonds with foreign countries: Does consumer affinity affect behavioural intentions? Journal of International Marketing, 19 (2), 45-72.

Oberecker, Eva, Petra Riefler, and Adamantios Diamantopoulos (2008), "The consumer affinity construct: Conceptualization, qualitative investigation, and research agenda, " Journal of International Marketing, 16 (3), 23-56.

Osborne, Jason W. and Anna B. Costello (2004), "Sample size and subject to item ratio in principal components analysis," Practical Assessment, Research \& Evaluation, 9 (11), 1-15.

Papadopoulos, Nicolas, Louise A. Heslop, and The IKON Research Group (2000), "A CrossNational and Longitudinal Study of Product-Country Images with a Focus on the U.S. and Japan," Marketing Science Institute Reports, no. 00-106. Cambridge, MA: Marketing Science Institute.

Parameswaran, Ravi, and R. Mohan Pisharodi (1994), "Facets of country of origin image: an empirical assessment, " Journal of Advertising, 23 (1), 43-56.

Peñaloza, Lisa (1994), "Atravesando fronteras/border crossings: A critical ethnographic exploration of the consumer acculturation of Mexican immigrants, " Journal of Consumer Research, 2 (1), 32-54. 
Pires, Guilherme, John Stanton, and Bruce Cheek (2003), "Identifying and reaching an ethnic market: methodological issues," Qualitative Market Research: An International Journal, 6 (4), 224-235.

Podoshen, Jeffrey (2009), "Distressing events and future purchase decisions: Jewish consumers and the holocaust," Journal of Consumer Marketing, 26 (4), 263-276.

Rezvani, Samin, Goodarz Javadian Dehkordi, Muhammad Sabbir Rahman, Firoozeh Fouladivandal, Mahsa Habibi, and Sanaz Eghtebasi (2012), "A Conceptual Study on the Country of Origin Effect on Consumer Purchase Intention," Asian Social Science, 8 (12), 205-215.

Riefler, Petra, and Adamantios Diamantopoulos (2007), "Consumer animosity: a literature review and a reconsideration of its measurement," International Marketing Review, 24 (1), 87-119.

Roth, Katharina P., and Adamantios Diamantopoulos (2009), "Advancing the country image construct," Journal of Business Research, 62 (7), 726-740.

Russel, James A. and James M. Carroll (1999), "On the bipolarity of positive and negative affect," Psychological Bulletin, 125 (1), 3-30.

Samiee, Saeed (2011), "Resolving the impasse regarding research on the origins of products and brands, "International Marketing Review, 28 (5), 473 - 485. 
Shay, Jeffrey P., and Sally A. Baack (2004), "Expatriate assignment, adjustment and effectiveness: an empirical examination of the big picture, " Journal of International Business Studies, 35 (3), 216-232.

Shiha, Tse-Hua, and Xitao Fan (2009), "Comparing response rates in e-mail and paper surveys: A meta-analysis," Educational Research Review, 4 (1), 26-40.

Shimp, Terence A., Tracy H. Dunn, and Jill G. Klein (2004), "Remnants of the U.S. Civil War and Modern Consumer Behavior," Psychology \& Marketing, 21 (2), 75-91.

Shoham, Aviv, and Yossi Gavish (2016), "Antecedents and Buying Behavior Consequences of Consumer Racism, National Identification, Consumer Animosity, and Consumer Ethnocentrism," Journal of International Consumer Marketing, 28 (5), 296-308.

Shoham, Aviv, Moshe Davidow, Jill G. Klein, and Ayalla Ruvio (2006), "Animosity on the home front: The intifada in Israel and its impact on consumer behaviour," Journal of International Marketing, 14 (3), 92-114.

Statistics Canada (2007), "The Arab Community in Canada," www.statcan.gc.ca/pub/89-621x/89-621-x2007009-eng.htm; accessed August 8, 2014.

Statistics Canada (2011), "National Household Survey: Data tables," NHS Profile, Canada, 2011. 
Stevens, James P. (2002), Applied multivariate statistics for the social sciences ( $4^{\text {th }}$ edition). Mahwah, NJ: Lawrence Erlbaum Associates.

Swift, Jonathan S. (1999), "Cultural closeness as a facet of cultural affinity: a contribution to the theory of psychic distance," International Marketing Review, 16 (3), 182-201.

Tajfel, Henri (1982), "Social psychology of intergroup relations," Annual Review of Psychology, $33,1-39$.

Ting-Toomey, Stella (2005), "Identity negotiation theory: Crossing cultural boundaries", in Theorizing about intercultural communication, W.B. Gudykunst, ed. Thousand Oaks, CA: Sage, 211-233.

Touzani, Mourad, Fatma Smaoui, and Mouna Meriem Labidi (2015), "Country-of-origin and emerging countries: revisiting a complex relationship," Qualitative Market Research, 18 (1), 4868.

Vida, Irena, and James Reardon (2008), "Domestic consumption: rational, affective or normative choice?," Journal of Consumer Marketing, 25 (1), 34-44.

Wang, Jay (2005), "Consumer nationalism and corporate reputation management in the global era," Corporate Communications: An International Journal, 10 (3), 223-239. 
Wohl, Michael J.A., Nyla R. Branscombe, and Yechiel Klar (2006), "Collective guilt: Emotional reactions when one's group has done wrong or been wronged," European Review of Social Psychology, 17), 1-37.

Worthington, Roger L., and Tiffany A. Whittaker (2006), "Scale development research a content analysis and recommendations for best practices," The Counseling Psychologist, 34 (6), 806-838.

Yang, Jun, Enping Mai, and Joseph Ben-Ur (2012), "Did you tell me the truth? The influence of online community on eWOM," International Journal of Market Research, 54 (3), 369-389.

Yang, Zhilin, Xuehua Wang, and Chenting Su (2006), "A review of research methodologies in international business," International Business Review, 15 (6), 601-617.

Yaprak, Attila (2008), "Culture study in international marketing: a critical review and suggestions for future research," International Marketing Review, 25 (2), 215-229.

Zeugner-Roth, Katharina P., and Vesna Žabkar (2015), "Bridging the gap between country and destination image: Assessing common facets and their predictive validity, "Journal of Business Research, 68 (9), 1844-1853.

Zeugner-Roth, Katharina P., Vesna Žabkar, and Adamantios Diamantopoulos (2015), "Consumer Ethnocentrism, National Identity, and Consumer Cosmopolitanism as Drivers of Consumer Behavior: A Social Identity Theory Perspective," Journal of International Marketing, 23 (2), 2554. 